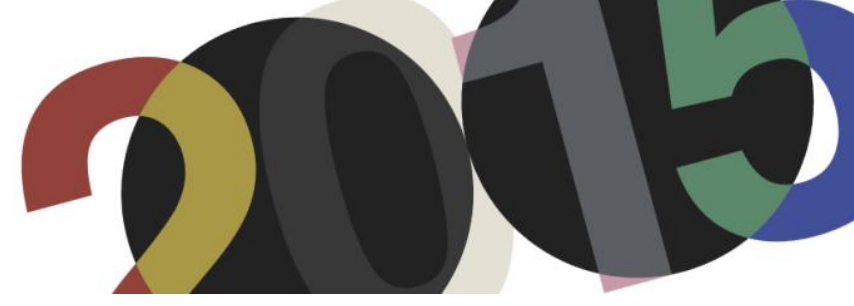

DOI: http://dx.doi.org/10.4995/LC2015.2015.992

\title{
INFLUENCIAS PINTORESCAS DE LE CORBUSIER EN EL PABELLÓN BRASILEÑO DE OSAKA`70
}

\author{
S. García-Gasco Lominchar \\ Escuela Superior de Arquitectura de Valencia, Universitat Politècnica de València, UPV \\ PROARQ. Universidade Federal do Rio de Janeiro, UFRJ
}

\begin{abstract}
Resumen: Iñaki Ábalos, en su libro "Atlas pintoresco" traza una línea de investigación sobre el Movimiento Moderno y su relación con la naturaleza y el paisaje. El autor establece un análisis en el que desenmascara los elementos pintorescos en la obra de Le Corbusier de manera que, aun apareciendo muchos de ellos en estado "latente" desde sus primeros postulados teóricos, paulatinamente y "casi de forma secreta" se irán adueñando de su modo de proyectar hasta conquistar todas las escalas de la arquitectura en su etapa final.

Algunas de las características arquitectónicas de la llamada Escuela Paulista parecen ser a su vez influencia de la obra tardía de Le Corbusier. El pabellón de Paulo Mendes para la Exposición Universal de Osaka'70 nos sirve en este artículo para establecer un análisis de determinados aspectos pintorescos de Le Corbusier que subyacen en la arquitectura brasileña en general y de Paulo Mendes en particular.
\end{abstract}

Abstract: Iñaki Abalos develop in "Atlas pintoresco" a research about Modern Movement and its relationship with nature and landscape. The author provides an analysis which unmask the picturesque elements in the work of Le Corbusier. These elements, even being "latent" in its earliest theoretical postulates, gradually and "almost secretly" will take over his way of projecting to conquer all scales of architecture in its final stage.

Some of the architectural features of the so-called Paulista School seems to have influences of the later work of Le Corbusier. Paulo Mendes pavilion for the World Expo Osaka'70 can serve to establish an analysis of some of the picturesque aspects of Le Corbusier underlying brazilian architecture in general and Paulo Mendes in particular.

Palabras clave: Pintoresco; Escola Paulista ; Le Corbusier; Paulo Mendes da Rocha; Naturaleza; Paisaje. Keywords: Picturesque; Paulista School; Le Corbusier; Paulo Mendes da Rocha; Nature; Landscape. 


\section{Introducción}

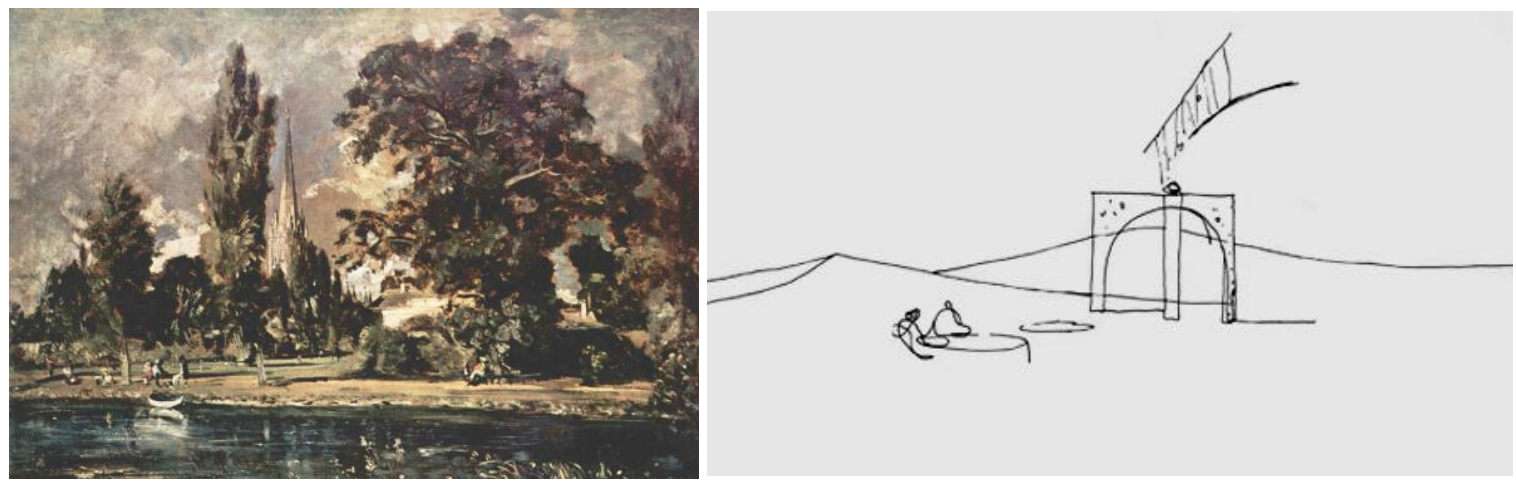

1. La Catedral de Salisbury vista desde el rio. John Constable. 1820

2. Boceto del pabellón de Brasil para Osaka’70. Paulo Mendes da Rocha. 1969

Tenemos, por un lado, el cuadro La Catedral de Salisbury vista desde el rio de John Constable. A su lado se encuentra uno de los esbozos que Paulo Mendes realizó para materializar la idea del proyecto del pabellón nacional de Brasil en Osaka’70.

Si comparamos las dos imágenes podemos observar algunas similitudes obvias: en ambas aparece representado un paisaje. Constable representa una escena típicamente pintoresca ${ }^{1}$ protagonizada por el cauce de un rio de aguas tranquilas rodeado de una vegetación bucólica y amable. De fondo, la Catedral de Salisbury aparece en el centro de la escena, entre las copas de los árboles. Su presencia no es meramente casual: Constable está persiguiendo el contraste entre una naturaleza en estado primigenio y una construcción que representa la presencia del hombre en el lugar. La contraposición entre naturaleza y artificio. A la sombra de los arboles aparecen ciudadanos disfrutando del espacio natural, paseando a la vera del rio o tumbados en la hierba. El cielo tormentoso de fondo contrasta con la luz dorada en primer plano, que transmite tranquilidad y sosiego. Los trazos rápidos y abocetados del pintor indican su interés por la transmisión de ciertas sensaciones y no tanto su representación formal.

Observando el boceto de Paulo Mendes, a pesar de pertenecer a técnicas de representación muy distintas y realizadas en épocas diferentes, se puede encontrar en él la misma alusión a la relación naturaleza-artificio que aparece en el cuadro de Constable: unas suaves colinas y un gran pilar conformado por dos arcos en cruz representan, en palabras de Paulo Mendes, la naturaleza en contraste con la ciudad ${ }^{2}$. El encuadre de la composición responde al mismo esquema: la construcción aparece en la parte central del dibujo, mientras que la línea del horizonte de las colinas desaparece en los límites de la escena. En el tercio izquierdo del diseño, un grupo de personas aparecen tranquilamente sentadas en la pendiente de una de las colinas. Parecen disfrutar del lugar y observar la construcción de fondo. Junto a ellos aparecen dos círculos que no están definidos en el proyecto. Ateniéndose únicamente al análisis del boceto, se puede interpretar en ellos dos pequeños estanques junto a los que están sentadas las personas representadas.

\footnotetext{
${ }^{1}$ Pintoresco, ca. (De pintor).

1. adj. Se dice de los paisajes, escenas, tipos, costumbres y de cuanto puede presentar una imagen peculiar y con cualidades plásticas.

2. adj. Se dice del lenguaje, estilo, etc., con que se pintan viva y animadamente las cosas.

Fuente: R.A.E

3. adj. Estrafalario, chocante.

${ }^{2}$ Macadar, Andrea. Paulo Mendes da Rocha. Entrevista, São Paulo: Vitruvius, ano 07, n. 026.02, abr. 2006 Cap. 3
} 
Ambas imágenes comparten una clara analogía representativa. Las dos reproducen escenas bucólicas de carácter contemplativo.

¿Existe alguna relación entre Paulo Mendes y el pintoresquismo inglés de principios del XIX?

Es difícil establecer un enlace entre dos imágenes tan aparentemente opuestas. Incluso en el caso de existir una influencia real de Constable sobre el dibujo de Paulo Mendes cabría preguntarse si esa influencia no acaba en la expresión y el encuadre gráfico, sin más consecuencias. Sería razonable que la coincidencia, fruto de la asimilación de un bagaje cultural humanista del arquitecto, no tenga una influencia (consciente) sobre el proceso creativo que establece en su arquitectura. Sin embargo, ante esta comparativa que pueda parecer superficial, subyace una evidencia. En las dos imágenes aparece representado lo mismo: el contraste entre la naturaleza y la arquitectura, naturaleza y artificio, y la relación humana ante tal contraste. Paulo Mendes y John Constable dibujaron en esencia la misma imagen con 150 años de diferencia.

A pesar del radicalismo en los postulados del Movimiento Moderno en su relación con el lugar y la abstracción de su arquitectura, existieron formulaciones pintorescas dentro de la modernidad que no pudieron ser enunciadas correctamente por su contradicción con las propias bases del movimiento. Algunos de los arquitectos más representativos, como Le Corbusier, Bruno Taut o Mies Van der Rohe, entre otros, establecieron puentes entre la estética pintoresca y la ideología moderna ${ }^{3}$.

Iñaki Ábalos, en su libro Atlas pintoresco traza una línea de investigación sobre el asunto. El autor establece un análisis en el que desenmascara los elementos pintorescos en la obra de Le Corbusier, de manera que, aun apareciendo muchos de ellos en estado "latente" desde sus primeros postulados teóricos, paulatinamente y "casi de forma secreta" se irán adueñando de su modo de proyectar hasta conquistar todas las escalas de la arquitectura en su etapa final. Entre los elementos más representativos de ese pintoresquismo anunciado por Ábalos se encuentran tres grandes cuestiones que son características de la obra tardía de Le Corbusier: la alusión al lugar, o genius locci, la promenade architecturale y el uso del hormigón visto. Además, Ábalos señala dos etapas diferenciadas en los postulados teóricos del arquitecto: una primera etapa, positivista, con la creencia ciega en que el desarrollo social y tecnológico daría solución a los problemas del mundo: "La naturaleza como portadora de leyes físicas, precisamente las mismas leyes físicas que han permitido alumbrar el maquinismo" "y una etapa tardía, post-II Guerra Mundial, donde la naturaleza se torna paisaje sujeto a la percepción. Esta última concepción de la naturaleza es la que dará origen al Le Corbusier pintoresco que Iñaki Ábalos defiende.

Le Corbusier desarrollará en su segunda etapa algunas de sus obras más importantes: La Unité d’habitation de Marsella (1947), la capilla de Ronchamp (1955), la asamblea de Chandigarh (1951-1965), el convento de la Tourette (1959) o Saint Pierre de Firminy (1966-2007), recientemente acabada. Todas ellas se caracterizan por un alejamiento de las doctrinas maquinistas iniciales hacia un expresionismo más dramático y perceptivo. El ángulo recto pierde su hegemonía y el contraste prevalece sobre la claridad de las formas arquitectónicas. Es la etapa donde el arquitecto desarrolla los brise-soleil como sistemas para el control lumínico, pero también como elementos de composición expresiva. También toman protagonismo los llamados objetos de reacción poética, elementos orgánicos o alusiones a la curva femenina que le servirán de inspiración para la creación de formas

\footnotetext{
3 Ábalos, Iñaki. "Le Corbusier pintoresco: el pintoresquismo en la modernidad". En Atlas Pintoresco.Vol.2: Los viajes. Barcelona: Ed Gustavo Gili. 2005. p 115

${ }^{4}$ Ibídem, p. 121
} 
arquitectónicas. El uso del hormigón visto y la alusión a los volúmenes másicos y pesados frente a la levedad de la etapa anterior caracterizan estas obras, muchas de ellas muy ligadas al entorno donde se construyen.

Según Alan Colquhoun, el conflicto conceptual entre el desarrollo tecnológico y el idealismo estético tendente al clasicismo es lo que caracteriza la teoría de Le Corbusier ${ }^{5}$. La base que sustenta las teorías enunciadas por el arquitecto puede posicionarse entre estos dos puntos aparentemente opuestos. Le Corbusier se ve a sí mismo como arquitecto y artista, siendo estas dos facetas las que determinen su discurso. Colquhoun cita como influencias en su teoría los principios positivistas y constructivos representados por la tradición moderna, por un lado, y los postulados teóricos clasicistas del siglo XVIII, la influencia del libro de Henry Provensal "L'Art de demain" (1904) y la doctrina artesanal de su maestro Charles L'Epplatenier por otro. Serán las dos cuerdas que Le Corbusier tratará de anudar en el desarrollo de toda su obra.

Se ha escrito extensamente sobre la fuerte influencia que Le Corbusier ejerce en la implantación del Movimiento Moderno en Brasil ${ }^{6}$. Sin embargo, dicha influencia no será ejercida a lo largo de los años ni en el mismo lugar ni de la misma forma. El proceso histórico y la búsqueda de una identidad Brasileña se desarrollará de forma linear y en ciudades diferentes, comenzando en Rio de Janeiro como capital del país, donde un Le Corbusier "purista" ayudará a proyectar el primer gran edificio moderno de Brasil: el Ministerio de Educación y Ciencia (MEC). En el edificio aparecen reflejados los cinco puntos de Le Corbusier para una arquitectura moderna: planta libre, suelo liberado a través de pilotis, independencia estructura-cerramiento, cubierta jardín, fachada libre. A partir del primer contacto de Le Corbusier con Brasil en 1929, se sucederán otros tantos en forma de visitas o cartas personales, dando lugar a múltiples y ricos intercambios que los arquitectos brasileños utilizarán para formalizar su propia modernidad. Al mismo tiempo, Le Corbusier absorberá de Rio un concepto muy importante en su discurso posterior: La presencia de la naturaleza y el paisaje en el proyecto. Décadas más tarde en São Paulo, la arquitectura paulista desarrollada en los años 60 estará fuertemente influenciada por la obra tardía del arquitecto a través de Vilanova de Artigas y la Escuela Paulista ${ }^{7}$. Vilanova combinó el aspecto crítico de aquella revisión de la utopía maquinista hecha por el maestro francosuizo en el contexto amargo de la II Guerra Mundial, con una visión claramente marxista en el que la exhibición de las huellas del encofrado de madera en el hormigón armado aparecerían como señales del trabajo hecho en obra, evitando el refinamiento fetichista de la construcción acabada ${ }^{8}$. Son muchos los matices que podrían ser analizados ante esta afirmación ${ }^{9}$, pero no nos desviaremos y la aceptaremos como una verdad ampliamente reconocida. Lo que parece evidente, como así lo refleja Lucio Costa, es el impacto que produce el cambio de rumbo que emprende Le Corbusier entre los arquitectos brasileños:

\footnotetext{
${ }^{5}$ Colquhoun, Alan. Modernity and the Classical Tradition: Architectural Essays 1980-1987. Cambridge (MA): MIT Press. 1989.

${ }^{6}$ No siendo conveniente en este caso entrar en la demostración de dicho discurso para no desviar nuestra atención.

${ }^{7}$ Tomaremos como referencia los aspectos sobre la "Escuela Paulista" que Ruth Verde Zein establece en su Tesis doctoral: Léase el apartado "2.2. Abecedário das características da arquitetura da Escola Paulista Brutalista" En Zein, Ruth Verde. A arquitetura da escola paulista Brutalista .1953 - 1973. Porto Alegre: UFRGS, 2005. 358 p. Tese (Doutorado) - Programa de Pós-Graduação em Educação, Faculdade de Educação, Universidade Federal do Rio Grande do Sul, Porto Alegre: 2005, p 33

${ }^{8}$ Wisnik, Guilherme. "Urbanizar la vida: una técnica comprometida". En AV monografías 161: Paulo Mendes da Rocha. Madrid: 2013, pp 13

${ }^{9}$ Existen diferentes motivaciones por detrás del uso del hormigón visto en la arquitectura. Uno de ellos puede ser el expuesto por Artigas. Le Corbusier no parece compartir tanto dichas motivaciones socio-políticas como la propia cuestión estética y expresiva de material expuesto.
} 
“(...) me quede sin palabras. (...) de repente comenzaron los pilotis enormes, toda aquella masa. (...) Entonces, después de muchos años, percibi que era una cosa humanística, una concepción" (...) "Fue un cambio inesperado, pues antes era una línea muy estructural, muy industrial y de producto. (...) Sólo un artista plástico podría hacer todas aquellas formas con una seguridad total" Lucio Costa ${ }^{10}$

Siendo una tarea inabarcable para un artículo de este tamaño el establecer las características de toda arquitectura paulista de los 60, podemos conformarnos con centrarnos en una obra que pueda representarla dignamente.

El pabellón de Paulo Mendes para la Exposición Universal de Osaka`70, con el que hemos comenzado el texto, nos puede servir para establecer en él un análisis de los aspectos pintorescos que pueden haber surgido dentro de la concepción de esta obra y poder entenderlos en un contexto más amplio.

\section{Osaka'70. La representación internacional de una arquitectura brasileña.}

El pabellón de Osaka fue construido para representar a Brasil en la Exposición Universal que tuvo lugar en Japón en 1970. Fue convocado a través de un concurso público nacional. Con tan solo 25 días para presentar las ideas, el proyecto ganador resulta de la autoría de Paulo Mendes da Rocha, Jorge Caron, Júlio Katinsky y Ruy Ohtake con la participación de un gran número de colaboradores arquitectos, estudiantes y artistas plásticos. También participa en su concepción el filósofo Flavio Motta.

La propuesta ganadora proponía una idea muy clara: Un gran espacio de convivencia generado por una cubierta de hormigón. Dicha cubierta se apoya sobre una suave topografía creada en forma de tres colinas. En el interior de la parcela se configura el llamado "Largo do café", una plaza protegida por la cubierta y delimitada por las colinas. Desde la avenida del recinto de la Expo, una rampa descendiente y oblicua a la cubierta permite la entrada a los espacios de exposición subterráneos, continuando su recorrido bajo tierra para acabar de nuevo en la superficie, en el centro de la plaza. La estructura se destaca por sus grandes dimensiones (32,5 x $50 \mathrm{~m}$ ) y sus voladizos. Tres de los cuatro pilares que la soportan se encuentran dentro de las colinas, transmitiendo la sensación de que la cubierta se apoya sobre ellas. El cuarto pilar protagoniza el espacio de la plaza interna. Se trata de un gran pilar en forma de dos arcos cruzados que generan un espacio abovedado. La cubierta está compuesta por un gran número de claraboyas que permiten la entrada de luz pero protegen de la lluvia. Para completar el programa, otro espacio subterráneo destinado a administración cierra el fondo de la parcela. Se accede a él por una rampa tangencial e intencionadamente discreta.

El proyecto se destaca por su homogeneidad constructiva, destacando el hormigón visto de la cubierta y el asfalto para conformar la topografía ondulante.

Según las palabras del propio jurado, el proyecto representa una "poética inconfundible muy ligada a una arquitectura brasileña", con un abordaje "nítidamente brasileño" basado en la liberación del suelo. ${ }^{11}$

En cierto modo, la propia finalidad del proyecto le confiere de antemano un papel representativo de "lo Brasileño" frente al mundo, y su selección como pabellón lo legitima de manera "oficial" como arquitectura de identidad nacional. Entendamos ahora cuales son las características que lo definen como "nítidamente brasileño". Antes de seguir, debemos dejar claro el hecho generalista que supone algo tan complejo como la

\footnotetext{
${ }^{10}$ Costa, Lúcio. "Presença de Le Corbusier, entrevista a J. Czajkowski, M. C. Burlamaqui e R. Brito", Revista Arquitetura. Rio de Janeiro: FAU/UFRJ 1987. Traducción propia.

${ }^{11}$ Acta del jurado, publicada en la revista Acrópole, № 361, 1969, p. 13 En Zein, Ruth Verde, Amaral, Izabel. "A Feira Mundial De Osaka de 1970: O Pavilhão Brasileiro". Arquitextos $N^{o}$ 16. Porto Alegre: UFRGS. PROPAR. 2011, pp 4. Traducción propia.
} 
búsqueda de una arquitectura nacional, más si cabe a través de una única obra. Sin embargo, parece razonable que en un determinado contexto geográfico y temporal, junto a unas influencias que puedan ser compartidas, se generen respuestas similares a problemas comunes, lo que puede derivar en la creación de una identidad propia. No en tanto, el tema de una arquitectura brasileña supondría una investigación que se sale del objetivo principal del texto, por lo que podremos asumir como estrategia ciertas afirmaciones que ya han sido escritas para continuar.

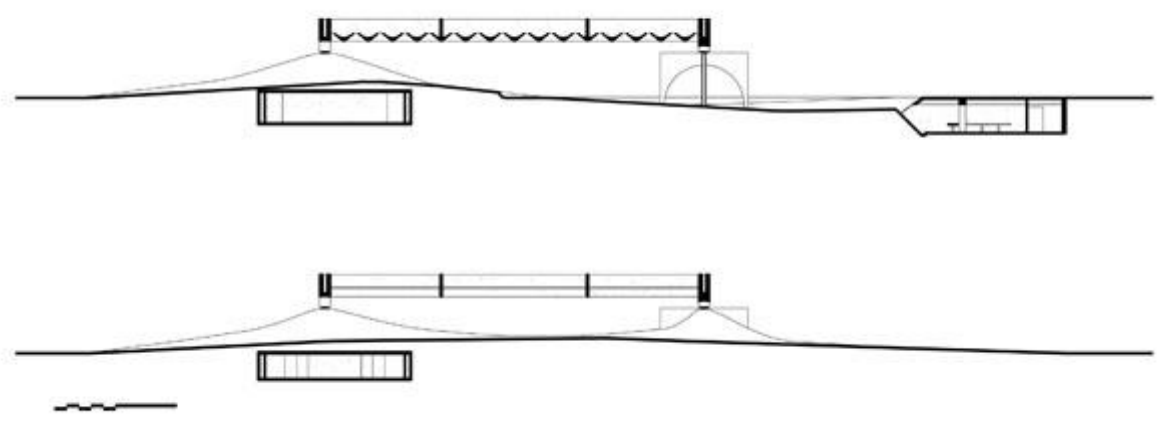

3. Sección transversal de la cubierta del pabellón.

Parece clara la asunción de la planta libre como una característica propia de Brasil por parte del jurado. Otros autores, como Ruth Verde Zein, también le otorgan un carácter representativo “(...) esta obra notable del Brutalismo Paulista, que genera una discusión sobre la identidad brasileña, terminó volviéndose de hecho en una referencia de la identidad arquitectónica nacional ${ }^{, 12}$.

Asumamos entonces estas hipótesis y analicemos cuales serían sus características.

Sin extendernos en las cuestiones políticas y económicas de Brasil en el momento de su construcción, es por lo menos importante remarcar la situación de aislamiento internacional y desaceleración económica que vive Brasil después de una etapa desarrollista que culmina con el golpe militar de 1964. La arquitectura brasileña, años antes elogiada en el mundo y puntera en el desarrollo tecnológico del hormigón, sufre ahora una etapa de aislamiento, al tiempo que las pautas disciplinares del Movimiento Moderno comienzan a agotarse ${ }^{13}$. No se trata de una situación particular de Brasil. Se trata de un momento de transición en el que el Movimiento Moderno está sufriendo desde hace décadas una profunda revisión.

En el mundo, esta revisión está dando paso a otras tipologías y técnicas constructivas experimentales que van a ser expuestas en Osaka. Prevalece en los pabellones el uso de estructuras metálicas tridimensionales y de cerramientos livianos, como los textiles, algunos de ellos resultado de avances tecnológicos en otros campos (para situarnos en el contexto, recordemos que en el pabellón de Estados Unidos el tema principal es la llegada a la Luna). Sin embargo, la hegemonía del hormigón visto en Brasil continúa siendo indiscutible y su desarrollo tecnológico continúa desde el inicio del Movimiento Moderno. En este contexto el jurado del concurso siente que el país no será capaz de destacarse por nuevas técnicas. Puede leerse en el discurso del jurado un cierto sentimiento "derrotista" y conservador:

$\begin{array}{ll}{ }^{12} & \text { Idem } \\ & \\ & \text { Ibidem. pp } 6\end{array}$ 
"Muchos concursantes se dejaron llevar por los aspectos técnicos del pabellón. Como Brasil no pretende competir con los países desarrollados (EUA y URSS gastarán cerca de 30 millones de dólares con sus pabellones), este énfasis sobre el lado tecnológico fue descartado",14
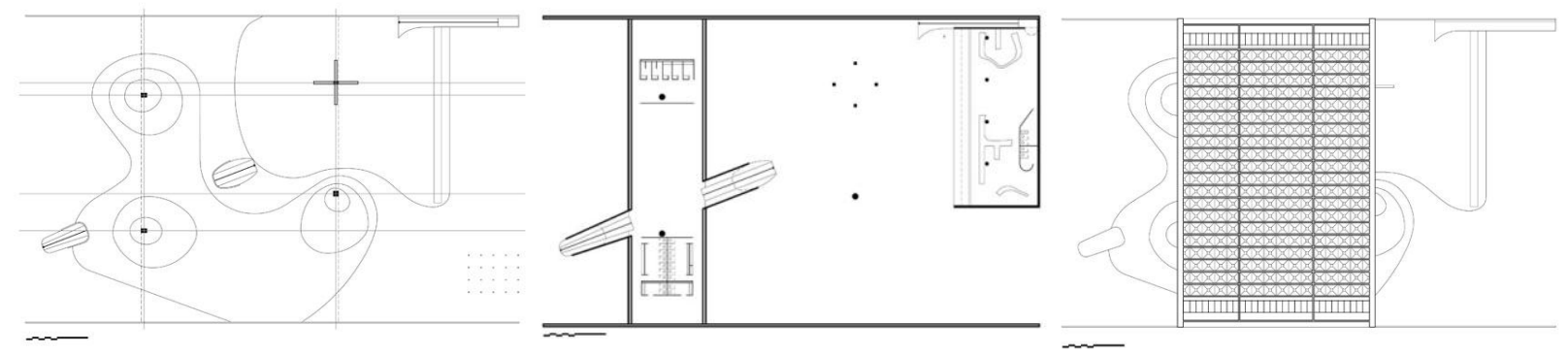

4. cubierta, planta y subsuelo del pabellón de Osaka.

El desarrollo técnico del hormigón en Brasil permite durante las décadas del 30 al 60 el uso de una herramienta de construcción eficaz que, junto con el apoyo de algunos ingenieros con sensibilidad arquitectónica, dará como resultado la Arquitectura Moderna Brasileña internacionalmente reconocida. Es por tanto razonable que, en una etapa donde el país se ha "descolgado" del tren de la tecnología y su arquitectura va a quedar expuesta ante el mundo nuevamente, se opte por hacer lo que mejor se sabe hacer: construir con hormigón.

Quizá en eso estén de acuerdo el jurado y el autor. Para Paulo Mendes, la cuestión de la identidad arquitectónica brasileña está relacionada íntimamente con la tecnología que el jurado quería para representar al país. Lo que Brasil podría ofrecer al mundo no era una nueva y original forma, si no el bagaje tecnológico que permite la construcción de esa forma. Como Paulo Mendes afirma "El pabellón representa un conocimiento, desarrollo

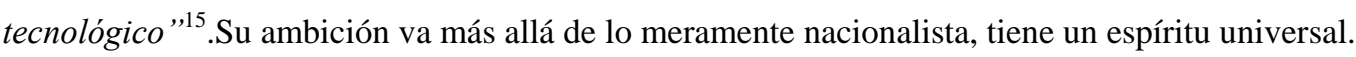

El tema de la gran cubierta que genera un espacio donde el espacio público se desarrolla es ya recurrente en la arquitectura Brasileña del año 69, una formulación importada por Le Corbusier que tiene sentido en el clima brasileño. Paulo Mendes habrá sido influenciado por la cubierta de la FAUSP (1961), un espacio concebido para el conocimiento y el desarrollo intelectual y social. Incluso antes, otros edificios urbanos como la marquesina del parque de Ibiriapuera de Niemeyer (1951) o el Museo de Arte Moderno de Rio, MAM (1953) habrán ofrecido ejemplos de un gran espacio libre y urbano donde todo acontece. No hace falta buscar en otros arquitectos para encontrar la misma referencia. El propio Paulo Mendes, 11 años antes, habría ganado el concurso para construir el Gimnasio Paulistano (1958) con una estructura que se resume de nuevo en un espacio cubierto y abierto a la ciudad, un edificio polivalente que en palabras de Paulo Mendes era "como hacer un bonito teatro en aquel lugar que sirviera para eventos deportivos, o para cualquier otra cosa" Paulo Mendes da Rocha ${ }^{16}$.

Existe detrás de este concepto un posicionamiento humanístico que debe tenerse en cuenta. En clave social el pabellón pretende, con su configuración abierta, generar un espacio para el ser humano, un lugar de encuentro concebido en un ejercicio de libertad. Postulados propios de Vilanova de Artigas que está presente en este

\footnotetext{
${ }^{14}$ Acta del jurado para el pabellón Brasileño de Osaka 70 . Op. Cit. Traducción propia.

15 Macadar, Andrea. Op. Cit.

${ }^{16}$ Mas, Vicente y otros. "Conversaciones con Paulo Mendes da Rocha". Revista Enblanco 14. Valencia: Ed. Generales de la Construcción. 2014
} 
proyecto de una manera literal: "Simbólicamente era un techo ideal, sería el techo de nuestra FAU colocado sobre el propio paisaje, que sería el paisaje simulado por aquellas colinas" Paulo Mendes da Rocha ${ }^{17}$.

Como veremos más adelante, el binomio técnica y naturaleza es para Paulo Mendes una base generadora de la arquitectura. La técnica es la herramienta con la que el arquitecto dialoga con la naturaleza y manipula sus leyes, la transforma y evidencia el poder del hombre frente a ella. Como él, un grupo de arquitectos brasileños establece en algunas obras de inicio de los 50 a los 70 una relación dialéctica entre arquitectura y gravedad a través de la técnica. En las palabras de Vilanova Artigas "Arquitectura, básicamente, es desafiar a ley de la gravedad. Eliminar apoyos, arrojar vanos..."18 pero este compromiso en negar la gravedad también es una forma de diálogo con la naturaleza a través de las condiciones gravitacionales. No se tratará pues de una mera hazaña estructural, sino de un posicionamiento humanístico. Desde el punto de vista de J.M del Monte en $L a$ poética de la gravedad, sin la técnica no existiría tal arquitectura, pero sin la base filosófica por detrás de ella resultaría fútil. ${ }^{19}$

\section{Aspectos pintorescos en el pabellón de Osaka.}

\subsection{Naturaleza y lugar}

La fuerte relación entre la arquitectura brasileña y la naturaleza es una de las características propias que mejor la definen. En palabras de Michel Racine "El movimiento moderno brasileño es un movimiento moderno con jardín ${ }^{, 20}$. Esa relación puede explicarse entendiendo la exuberancia del paisaje de un país enorme y joven que aún está en proceso de exploración. La topografía de Rio de Janeiro es de tal potencia que difícilmente puede doblegarse al hombre. Es el hombre quien se integra en esa naturaleza amable que hipnotiza por su presencia masiva. La monumentalidad y sensualidad del relieve Carioca impactará profundamente en Le Corbusier y afectará a su sistema proyectual. En su propuesta para la ciudad de Rio de Janeiro (1929), propone un edificio superestructural lineal de varios kilómetros que recorre todo el litoral por encima de la ciudad existente, adaptándose a la geografía. Se trata de un proyecto premonitorio donde aparece por primera vez un factor que determina el camino a seguir de Le Corbusier: La adaptación al lugar.

En el pabellón encontramos una topografía creada que también representa a la naturaleza. Evoca la monumentalidad de la geografía original ${ }^{21}$. Ya en la década del 70 la ciudad de Rio es mundialmente conocida por su belleza natural y representa la imagen más conocida de Brasil en el mundo. No es por casualidad entonces que se aluda a esa geografía que todos conocen para representar al país. Paulo Mendes toma así prestado un paisaje para su proyecto, pretendiendo trasportar al visitante al lugar representado. La cubierta también está cargada de simbolismo: representa la delimitación de la ciudad en esa naturaleza, marca simbólicamente el espacio "civilizado" dentro de un espacio natural mayor “(...) lo que aquel pabellón quería expresar, antes de

\footnotetext{
${ }^{17}$ Macadar, Andrea. Op.cit. Traducción propia.

${ }^{18}$ Ferraz, Marcelo Carvalho (Coord. Ed.)."Vilanova Artigas", Fundação Vilanova Artigas, Instituto Lina Bo e P.M. Bardi, São Paulo.1997 p.184

${ }^{19}$ Monte. Jose María Garcia del." Poética de la gravedad”. Revista del Colegio Oficial de Arquitectos de Madrid N $N^{o}$.356, Madrid: COAM, 2009. p. 71-80

${ }^{20}$ Racine, Michael en Leenhardt, Jacques (ed). Nos jardins de Burle Max. São Paulo: Editora Perspectiva,1994, pag 114

21 Habría quizá que especificar: geografía original Carioca. Wisnik, Guilherme. "Urbanizar la vida: una técnica comprometida". En AV monografías 161. Paulo Mendes da Rocha. Madrid: AV. 2013
} 
nada, era la conciencia de la ocupación de la naturaleza de América con las construcciones „22. La creación de una ciudad sobre el territorio es el concepto base del pabellón.

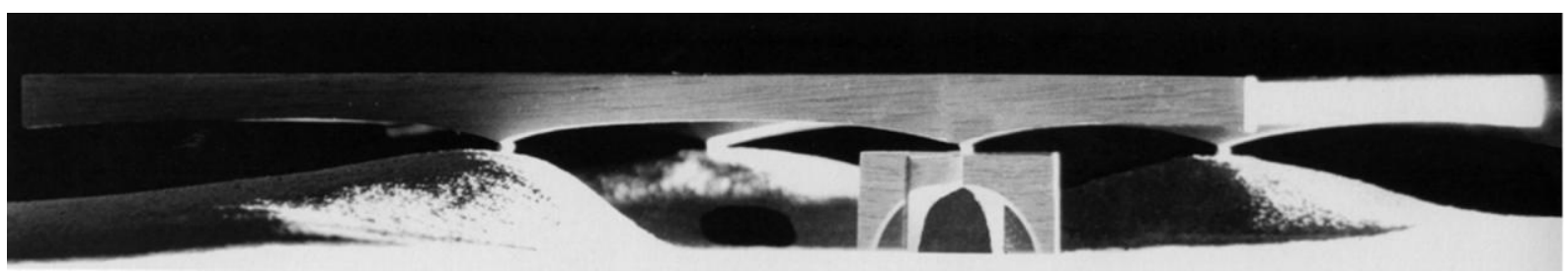

5. Pabellón de Osaka`70. Imagen de maqueta.

Para Paulo Mendes, la manera de actuar sobre el espacio pre-arquitectónico consiste en transformarlo para la creación de un espacio civilizado, la arquitectura precede a una necesidad humana y satisface sus deseos sobre un territorio.

“(...) la transformación del territorio como la parte fundamental da arquitectura, aquello que ampara proyectos que ya existen en nuestras mentes. Y que se hundirían en el pantanal sin esa reconfiguración del territorio - una nueva geografí, necesaria para sustentar los edificios, para caminar sobre lo que antes era manglar" Paulo Mendes da Rocha ${ }^{23}$

La arquitectura es por tanto una acción de elección del lugar primero y su manipulación después. Para Paulo Mendes, la belleza de Rio de Janeiro va más allá que la propia belleza del paisaje. Los espacios creados por la civilización, la abertura de avenidas, los aterros conquistados al mar, la utilización de su propia materia para manipularla es lo que la hace más bella a ojos del hombre y crea en el brasileño una conciencia sobre la posibilidad de modificar su naturaleza.

Difiere aquí del posicionamiento de Le Corbusier en su segunda etapa. En Argel, Ronchamp o la Tourette la relación de la arquitectura con el lugar pretende ser de respeto, dejando la naturaleza primigenia aparentemente “intocada”. Paulo Mendes actúa sobre el lugar y lo transforma según sus necesidades. Ambos posicionamientos persiguen el marco de una naturaleza "ideal" entendida de manera diferente. Toda obra construida implica una agresiva manipulación del lugar, la diferencia viene en las intenciones. La pendiente natural sobre la que se asienta el convento de La Tourette se introduce de manera continua por debajo del piloti, restaurando la preexistencia natural. Paulo Mendes manipula la topografía y deja evidencia de esa transformación, sin por ello no aludir a un estado natural. Encontramos una diferencia substancial: el arquitecto brasileño podría fácilmente haber echado mano de la vegetación para cubrir las colinas e imitar un espacio natural, un cliché que todo el mundo identificaría con Brasil. Prefirió sin embargo abstraer el concepto de naturaleza, dejar la evidencia de la manipulación del hombre sobre el paisaje artificialmente creado.

\footnotetext{
${ }^{22}$ Macadar, Andrea. Op. Cit. Traducción del autor.

${ }^{23}$ Mendes da Rocha, Paulo, en "A Natureza é um trambolho". Caros amigos $N^{o} 61$, abril 2002. Traducción del autor
} 


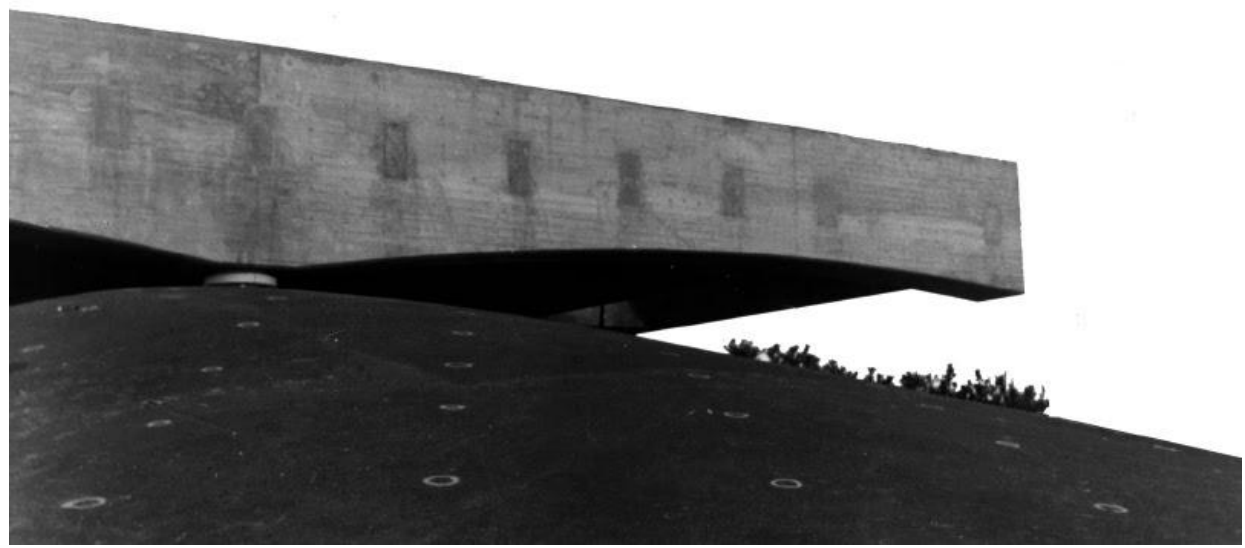

6. Imagen del pabellón construido.

La estructura de la cubierta del pabellón se apoya delicadamente sobre las 3 colinas diseñadas al milímetro para tal efecto. El resultando buscado es un estado de equilibrio armonioso entre la construcción y el espacio creado. Los arcos en los que se transforman las vigas testeras de la cubierta contribuyen a crear un diálogo entre las colinas y la cubierta. Ésta parece aproximarse delicadamente a la topografía en un gesto compartido por ambos elementos, que se tocan tímidamente en un sólo punto a través de un disco de transición. Esa pieza intermedia es la frontera que separa lo construido de la "naturaleza primigenia" creada. Encontramos en la relación de los dos elementos principales del proyecto un paralelismo con el binomio naturaleza-artificio que establecen los preceptos pintorescos. En este juego representaciones del pabellón, Paulo Mendes llama a la construcción, y concretamente al pilar abovedado "la ciudad" mientras que a la topografía la llama naturaleza ${ }^{24}$. Se establece un contraste con la misma intención con la que Constable deja aparecer la catedral entre las copas de los árboles de una forma armoniosa.

\subsection{Promenade Architecturale}

La relación del visitante con la obra también merece nuestra atención. Desde fuera de la parcela, las colinas que componen la llegada proponen al visitante unos recorridos hacia el interior del pabellón. Estos montículos son al mismo tiempo barrera y espacio de continuidad. La intención no es casual: deliberadamente el proyecto no tiene una fachada materializada, sino que podría ser un continuo infinito con múltiples posibilidades de acercamiento. El hecho de que los pilares interiores y exteriores estén dislocados ayuda a potenciar la sensación de un espacio libre y sin corsés geométricos. Ese dislocamiento también ayuda a configurar un fondo visual desde fuera, al aparecer la colina trasera entre las dos delanteras. Con esta operación el Largo do Café queda delimitado y oculto por las tres elevaciones. Se intenta así potenciar el carácter sorpresivo del espacio en el que acaba el recorrido.

A medida que nos aproximamos existen dos formas de llegar hasta el fondo de la parcela: a través de la rampa subterránea o por la superficie rodeando las colinas. La rampa desciende suavemente hasta la sala de exposiciones para después volver a subir hasta aparecer a 40 metros de distancia, ya bajo la cubierta. El proceso de entrada se convierte así en un recorrido espacial lineal donde la relación compresión-descompresión, luz y sombra y espacio enterrado-superficie son los factores que transmiten la experiencia arquitectónica. El visitante que decide caminar por la superficie recorrerá un camino sinuoso e indefinido entre las colinas. A medida que se acerque experimentara el progresivo peso de la cubierta y la escala de sus vanos.

\footnotetext{
${ }^{24}$ Macadar, Andrea. Paulo Mendes da Rocha. Entrevista, Op. Cit.
} 
En ambos recorridos existe un estudiado proceso de entrada donde las sensaciones que provocan forman parte de la experiencia. El objeto arquitectónico como elemento sujeto a la percepción y la contemplación. La promenade architectural aparece claramente definida en ambas circulaciones. Si la rampa alude al dislocamiento y a la relación espacio-tiempo, el camino entre las colinas proporciona un ejemplo de la técnica del paralaje: A medida que el caminante se va acercando a la construcción, la relación del dos primeras colinas con la que queda en el interior y el pilar abovedado irá variando.

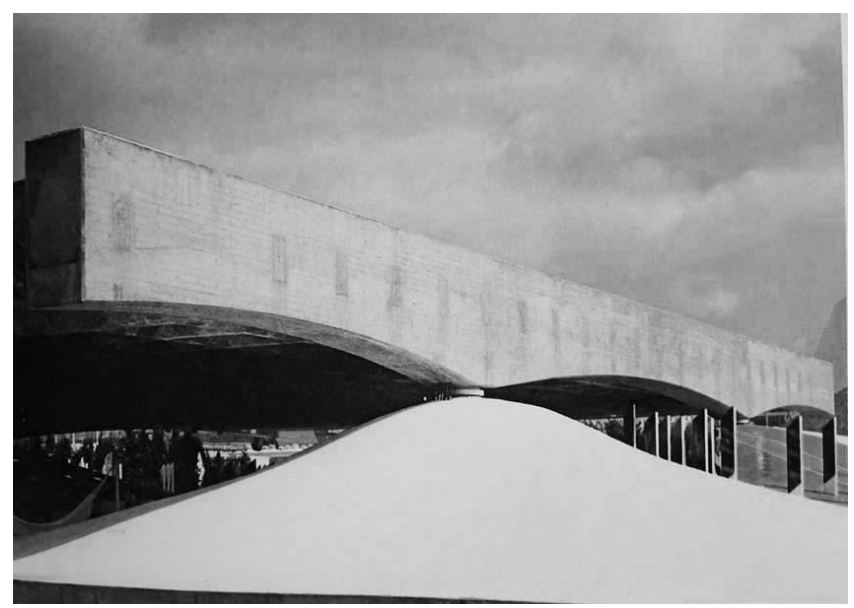

7. Feria de Osaka en funcionamiento.

\subsection{Naturaleza, Técnica y Gravedad}

“Arquitectura es, por encima de todo, el brillo del éxito de la técnica" Paulo Mendes da Rocha ${ }^{25}$

Volvamos a analizar la estructura desde un punto de vista técnico: La cubierta resuelve mediante una estructura pretensada la posibilidad de grandes vanos que generan un espacio libre de pilares. Al igual el piloti, los grandes vanos generados por nuevos sistemas estructurales habrán sido introducidos por Le Corbusier en su propuesta para el auditorio de la Universidad de Brasil (1929), donde proyectará unos arcos externos que sustentan a través de cables tensionados la cubierta del auditorio, liberando el interior de pilares. A partir de ese proyecto se sucederán en Brasil muchos otros sistemas estructurales que perseguirán dar solución a la necesidad de grandes vanos. El sistema nervado del pabellón responde con otro recurso estructural a la misma demanda de un gran espacio totalmente liberado.

La cuadrícula nervada genera una retícula de claraboyas que iluminan el espacio y lo protegen de la lluvia. La forma de los nervios estructurales resuelve a su vez la evacuación del agua de lluvia a través de los pilares. Este concepto, que viene de la cubierta de la FAU, es trasladado a Japón para demostrar el carácter universal de una tecnología creada para hacer frente a la naturaleza.

Sigamos con más detalles: La propia configuración de la cubierta, compuesta por un sistema voladizo-vanovoladizo permite el equilibrio sencillo de la estructura sin necesidad de grandes alardes estructurales. El pilar abovedado absorbe las cargas gravitatorias en un punto para transferirlo a 4 en el terreno. La desaparición del soporte en la parte central, donde naturalmente debería aparecer, ayuda a potenciar la idea de levitación de la cubierta. Tampoco está exento de contenido filosófico. Representa el esfuerzo de la humanidad por vencer a la

\footnotetext{
${ }^{25}$ Mas, Vicente y otros. "Conversaciones con Paulo Mendes da Rocha”. Revista Enblanco 14. Valencia: Ed. Generales de la Construcción. 2014
} 
naturaleza $^{26}$, la lucha contra la opresión de la gravedad. Sin embargo, detrás de las intenciones humanísticas de sus formas también subyace un motivo técnico: al tiempo que vence el peso de la cubierta, soportaría los terremotos mediante su gran resistencia a cortante. La técnica se ha aplicado al lugar y de nuevo se ha utilizado para manipular la naturaleza.

"De la voluntad de entender y transformar la naturaleza nace una arquitectura que la asume, pero para aprovechar su fuerza en su favor. El ensueño de la levedad que tenga a la gravedad como enemigo es escapista, ilusorio y, finalmente, imposible. Por eso, la arquitectura de la levedad ve a la gravedad como servidumbre, mientras que aquélla que la asume tiene las puertas abiertas para hacer de su dificultad e inevitabilidad motivo de su grandeza" Jose María García del Monte ${ }^{27}$

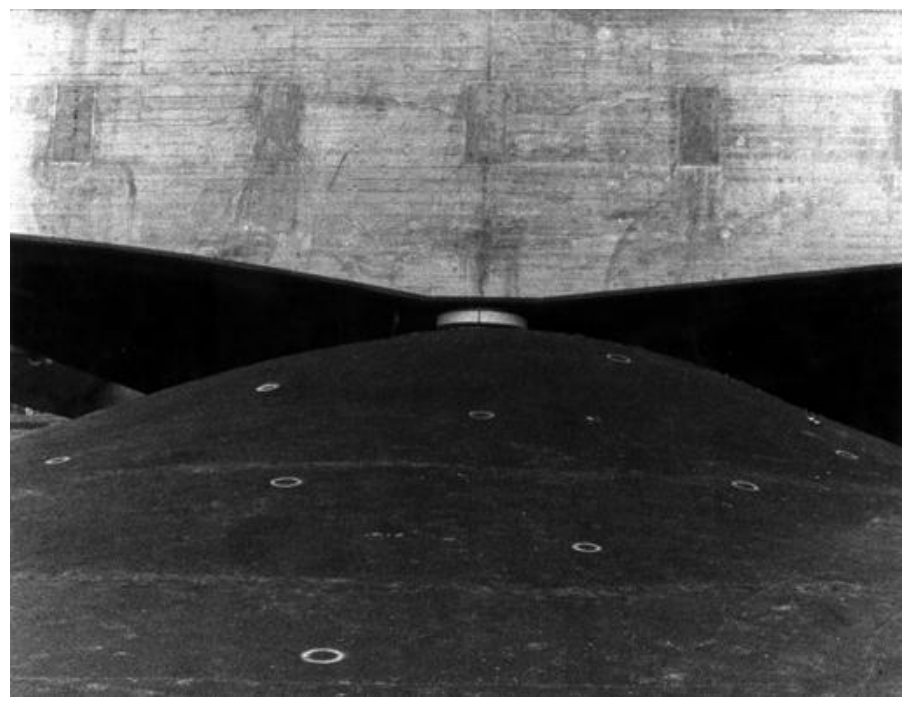

8. Detalle del contacto entre la colina y la cubierta.

\subsection{Acerca del hormigón visto}

“Después de la guerra tuve algunos encargos (...) tuve la ocasión de hacer, de utilizar por fin el hormigón. Por lo limitado de los presupuestos (...) hice hormigón bruto y en Marsella lo hice entre el 47 y el 52 (...) creo una revolución entre la gente e hice nacer un nuevo romanticismo, el romanticismo de "lo jodido" Le Corbusier ${ }^{28}$ La contrucción de la Unité de habitation de Marsella supone la aceptación de la imperfección del hormigón visto como material de expresión estructural y material. Este nuevo punto de vista se aleja de los principios modernos dictados por Le Corbusier décadas antes. Se trata de un acercamiento a posicionamientos estéticos que ya no serán abandonados. Acepta el fallo de ejecución como parte del romanticismo que implica el descubrimiento de las texturas después del desmoldaje, así como la expresividad y las sensaciones que el hormigón es capaz de

\footnotetext{
${ }^{26}$ Sperling, David. "Arquitetura como discurso. O Pavilhão Brasileiro em Osaka de Paulo Mendes da Rocha” En sitio web vitruvius.com.br, periódico “Arquitextos”, no 038.03. 2003

${ }^{27}$ Garcia del Monte, José Maria. Tesis doctoral. De las posibilidades arquitectónicas del pretensado. Madrid: UPM 2010.

${ }^{28}$ Le Corbusier. Entretiens avec George Charensol (1962) et Robert Mallet (1951). Paris : Frémeaux et associés, 2007. Traducción propia.
} 
transmitir a través de sus características. Se trata pues de un posicionamiento personal y por tanto subjetivo: "Aprovecho los recursos (del hormigón), por qué no, me divierte, me interesa", 29

Su maestro, Auguste Perret, del que heredará el conocimiento del material, habrá comenzado a utilizar el hormigón de forma vista mucho antes que él. Afirmaciones como "si la estructura no es digna de quedar vista, el arquitecto no ha hecho bien su misión" cualquier otro. Necesita ser trabajado, tratarlo como se trata la piedra" ${ }^{\prime \prime 1}$ sin duda calaron en el proceso de aprendizaje de Le Corbusier con su maestro, del que adquiere dos características clave que se derivan de esas dos afirmaciones: la valorización de la estructura expuesta y el uso del hormigón armado visto. Justamente dos de las características más representativas del pabellón de Osaka.

\subsection{Naturaleza de lo sublime}

La exaltación de la técnica por parte de Paulo Mendes conlleva un significado implícito acerca del dominio del hombre sobre la naturaleza. Pero esta explicación no sería completa si no se introdujese el factor la percepción y la emoción como otro de los elementos por detrás de la utilización de la técnica. Los grandes vanos y los volúmenes másicos fluctuantes que caracteriza las obras de Paulo Mendes (y también una buena parte de la brasileñas) suponen una demostración de la capacidad de rebelarse contra la gravedad, pero por detrás de esta manipulación subyace la emoción que nos provoca el desajuste del orden escalar establecido en nuestra conciencia, un sentimiento de inquietud, al mismo tiempo que de atracción por el objeto arquitectónico suspendido. Se trata de un sentimiento innato que tiene relación con la escala humana y el orden establecido por la naturaleza. Es el mismo sentimiento que el hombre prehistórico pudo sentir cuando colocó por primera vez una piedra horizontal sobre una vertical para construir el primer dolmen. El uso de hormigón visto y bruto consigue potenciar la idea de peso, de una gran piedra levitando sobre las colinas. Es quizá el efecto perseguido por Le Corbusier con la gran masa levitada de la Tourette sobre la ladera de la montaña, los grandes aleros de la asamblea de Chandigarh o la cubierta redondeada de hormigón visto en Ronchamp, que fluctúa sobre pesados muros estructurales.

En palabras de Kant:

"Rocas audazmente colgadas y, por decirlo así, amenazadoras, nubes de tormenta que se amontonan en el cielo y se adelantan con rayos y con truenos, volcanes en todo su poder devastador, huracanes que van dejando tras de sí desolación, el océano sin límites rugiendo de ira, una cascada profunda en un río poderoso, etc, reducen nuestra facultad de resistir a una insignificante pequeñez, comparada con su fuerza. (...) llamamos gustosos sublimes a esos objetos porque elevan las facultades del alma por encima de su término medio ordinario" Inmanuel Kant ${ }^{32}$

De nuevo, Kant alude a la naturaleza nombrando elementos que al compararlos con nosotros mismos nos transportan a un relación de escalas que nos provoca un sentimiento de inquietud. Para Kant, lo bello es un acto tranquilo de contemplación, lo sublime inquieta al espíritu humano y le causa temor. La línea que separa lo temible de lo sublime está en la experiencia. Para sentir lo sublime es necesario conocimiento.

\footnotetext{
${ }^{29}$ Idem. Traducción propia.

${ }^{30}$ Gargiani, Roberto. Aguste Perret. París: Gallimard/Electa. 1994. Pg 62-63

${ }^{31}$ Perret, Auguste. Anthologie des écrits, conferences et entretiens. Paris, Le Moniteur, 2006. Pg 208.

${ }^{32}$ Kant, Immanuel: Crítica del juicio (1790), Madrid, Espasa Calpe, Colección Austral, 1995. P. 205. Traducción propia.
} 
El sentimiento de lo sublime está intrínsecamente relacionado con la monumentalidad. La gran cubierta de Osaka es la herramienta intelectual con la que Paulo Mendes, además de resolver un problema arquitectónico, está queriendo provocar reacciones sensoriales en el visitante. La escala es el instrumento utilizado para provocarnos esta sensación, generando un efecto de monumentalidad en la estructura.

"Los monumentos arquitectónicos muestran su esfuerzo por alcanzar la perfección estructural que, en gran parte, ha contribuido a la claridad de su forma, la lógica de su escala, y su efecto perdurable” Louis Kahn ${ }^{33}$

Las estructuras nervadas de las catedrales góticas suponen la etapa histórica donde el hombre ha llegó al más alto nivel de desarrollo en relación a la construcción en piedra. Su reproducción no tendría sentido hoy, puesto que las aspiraciones con las que fueron construidas no se corresponden con las actuales. Sin embargo, podemos extraer de esas estructuras monumentales una lección: es el punto final de un camino de dialogo entre hombre y la gravedad a través de la piedra como lenguaje de interlocución. La experiencia acumulada de muchas generaciones conseguirá, a través de nuevos y continuos aportes tecnológicos, comprender la naturaleza de la piedra hasta poder manipular las leyes naturales para construir arcos y pilares de una esbeltez y tamaño nunca antes visto. De la misma manera que los constructores medievales utilizaron la piedra para crear ese diálogo, arquitectos brasileños como Paulo Mendes dialogarán con la gravedad a través del hormigón. En ambos casos el objetivo es el mismo, solo cambia la herramienta con la que se trabaja.

Cuando Paulo Mendes diseñó el pabellón de Osaka quiso, en definitiva, exportar una reflexión arquitectónica al mundo: La manera en que los arquitectos brasileños construyen su arquitectura a través de la técnica aplicada al hormigón armado. La relación dialéctica de estos dos conceptos está ligada con el posicionamiento pintoresco de la obra tardía de Le Corbusier, que se libera de la racionalidad de su primera etapa para plasmar en sus proyectos aspectos sensitivos relacionados con la escala, la monumentalidad, la percepción arquitectónica, la expresividad estructural y material del hormigón o la relación con la naturaleza y el paisaje.

\section{Procedencia de la imágenes}

Figura 1: National Gallery. http://www.nationalgallery.org.uk

Figura 2: Archivo del estudio de Paulo Mendes da Rocha

Figura 3: www.arquiteturabrutalista.com.br. Autor: Eduardo Pompeo Martins (cortesia de Ruth Verde Zein)

Figura 4: www.arquiteturabrutalista.com.br. Autor: Eduardo Pompeo Martins (cortesia de Ruth Verde Zein)

Figura 5: Archivo del estudio de Paulo Mendes da Rocha

Figura 6: Archivo del estudio de Paulo Mendes da Rocha

Figura 7: Archivo del estudio de Paulo Mendes da Rocha

Figura 8: Archivo del estudio de Paulo Mendes da Rocha

\section{Bibliografia}

Ábalos, Iñaki. Atlas Pintoresco. Barcelona: Ed Gustavo Gili. 2005.

Arantes, Carolina y otros. "A natureza é um trambolho. Entrevista a Paulo Mendes”. Caros amigos. No 61. São Paulo: Editora Caros Amigos 2002.

\footnotetext{
${ }^{33}$ Kahn, Louis. “Monumentalidad” (1944). Wrigting lectures. Milán: Ed Rizoli, 1991.
} 
Colquhoun, Alan. Modernidad y tradición clásica: ensayos sobre crítica arquitectónica. Madrid-Gijon: Ediciones Júcar, 1991. Originalmente en Modernity and the Classical Tradition: Architectural Essays 19801987. Mit Pr; 1989.

Costa, Lúcio. "Presença de Le Corbusier, entrevista a J. Czajkowski, M. C. Burlamaqui e R. Brito", Revista Arquitetura. Rio de Janeiro: FAU/UFRJ 1987.

Ferraz, Marcelo Carvalho (Coord. Ed.). "Vilanova Artigas", São Paulo: Fundação Vilanova Artigas, Instituto Lina Bo e P.M. Bardi.1997

Garcia del Monte, José Maria. De las posibilidades arquitectónicas del pretensado. Tesis doctoral. Dept. de Proyectos Arquitectónicos. ETSAM- UPM. Madrid. 2010

Gargiani, Roberto. Aguste Perret. París: Gallimard/Electa. 1994.

Kahn, Louis. "Monumentalidad” (1944). Wrigting lectures. Milán: Ed Rizzoli. 1991.

Kant, Immanuel: Crítica del juicio. Madrid, Espasa Calpe, Colección Austral, 1995

Le Corbusier. Por uma arquitetura. São Paulo: Ed perspectiva. 2013

Leenhardt, Jacques (ed). Nos jardins de Burle Max. São Paulo: Editora Perspectiva,1994

Macadar, Andrea. "Paulo Mendes da Rocha. Entrevista". En Vitruvius 07, n. 026.02, abr. São Paulo:

Vitruvius.2006

Mas,Vicente y otros "Conversaciones con Paulo Mendes da Rocha". Revista Enblanco No14. Valencia: Ed. General de la construcción. 2014

Monte. Jose María Garcia del.” Poética de la gravedad". En Revista del Colegio Oficial de Arquitectos de Madrid $N^{o}$. 356, Madrid: COAM, 2009.

Perret, Auguste. Anthologie des écrits, conferences et entretiens. Paris : Le Moniteur, 2006

Pisani, Daniele. Paulo Mendes da Rocha. Obra completa. Barcelona: Ed Gustavo Gili. 2013

Sperling, David. "Arquitetura como discurso. O Pavilhão Brasileiro em Osaka de Paulo Mendes da Rocha" En sitio web vitruvius.com.br, periódico “Arquitextos”, no 038.03. 2003

Wisnik, Guilherme. "Urbanizar la vida: una técnica comprometida" En AV monografías 161. Paulo Mendes da Rocha. Madrid: Arquitectura Viva. 2013

Zein, Ruth Verde, Aamaral, Izabel. “A Feira Mundial De Osaka de 1970: O Pavilhão Brasileiro” En Arquitextos $N^{o}$ 16. Porto Alegre: UFRGS. PROPAR. 2011

Zein, Ruth Verde. A arquitetura da Escola Paulista Brutalista .1953 - 1973. Tese (Doutorado) UFRGS. Programa de Pós-Graduação em Educação, Faculdade de Educação, Universidade Federal do Rio Grande do Sul, Porto Alegre, 2005

Zein, Ruth Verde. Brutalist connections. São Paulo: Ed. Altamira, 2014 